\title{
Prospects for digitalization of agricultural industries (using the example of an infrastructure block)
}

\author{
E.A. Leshchenko*, E.M. Basarygina, S.V. Cherepukhina, and G.P. Leshchenko \\ Federal State Budgetary Educational Institution of Higher Education "South Ural State Agrarian \\ University"(South Ural State Agrarian University), Chelyabinsk, Russia
}

\begin{abstract}
For the infrastructure block of the agro-industrial complex, a program has been developed that allows determining the rational air pressure in the tires of multi-axle wheeled vehicles. The developed software contributes to the transfer of the information block of the agro-industrial complex to a digital basis. Its use allows you to reduce fuel consumption, increase the economic efficiency and environmental friendliness of transportation. The use of software in the educational process makes it possible to form professional competencies of agribusiness specialists in accordance with Federal state educational standards and educational standards.
\end{abstract}

\section{Introduction}

Currently, the Russian Federation has adopted a package of strategic planning documents, which provides for the implementation of measures aimed at the development of digital technologies. Especially relevant is the use of digital technologies in the agro-industrial complex (AIC), which includes various sectors of the economy related to the production of agricultural products and their supply to consumers [1 - 9].

The complex of agricultural industries includes agriculture (animal husbandry, agriculture, crop production, etc.) and industries that closely interact with it [3 - 9], Figure 1.

Among the branches of the agro-industrial complex, an important place is occupied by the infrastructure block, which carries out transport transportation, which allows, on the one hand, to provide the population with food, and on the other - to implement continuous technological cycles [3]. The functionality of the infrastructure block also includes training of personnel for agriculture (Figure 1), which is currently carried out both in full-time format and with the use of digital technologies $[10 ; 11]$.

The program "Digital Economy of the Russian Federation" establishes that data in digital form will be the basis of production, and provides for the creation of a new technological basis for economic sectors $[1 ; 2]$.

A new technological basis for economic sectors, including the agro-industrial complex, can be implemented with the help of information and communication technologies and a set of programs that ensure the reliability and efficiency of various industries [1 - 9].

\footnotetext{
* Corresponding author: umu@sursau.ru
} 


\section{Goal and objectives.}

The purpose of the research was to improve the efficiency of the infrastructure block based on the use of digital technologies.

Research objectives:

- development of a mathematical model for calculating the rational tire pressure;

- development of a software product that allows you to determine the rational air pressure for wheeled vehicles with different sizes and models of tires;

- determination of the technical and economic efficiency of the technological operation to ensure the rational air pressure in the tires of wheeled vehicles;

- use of the created software product in the process of training qualified personnel for the agro-industrial complex.

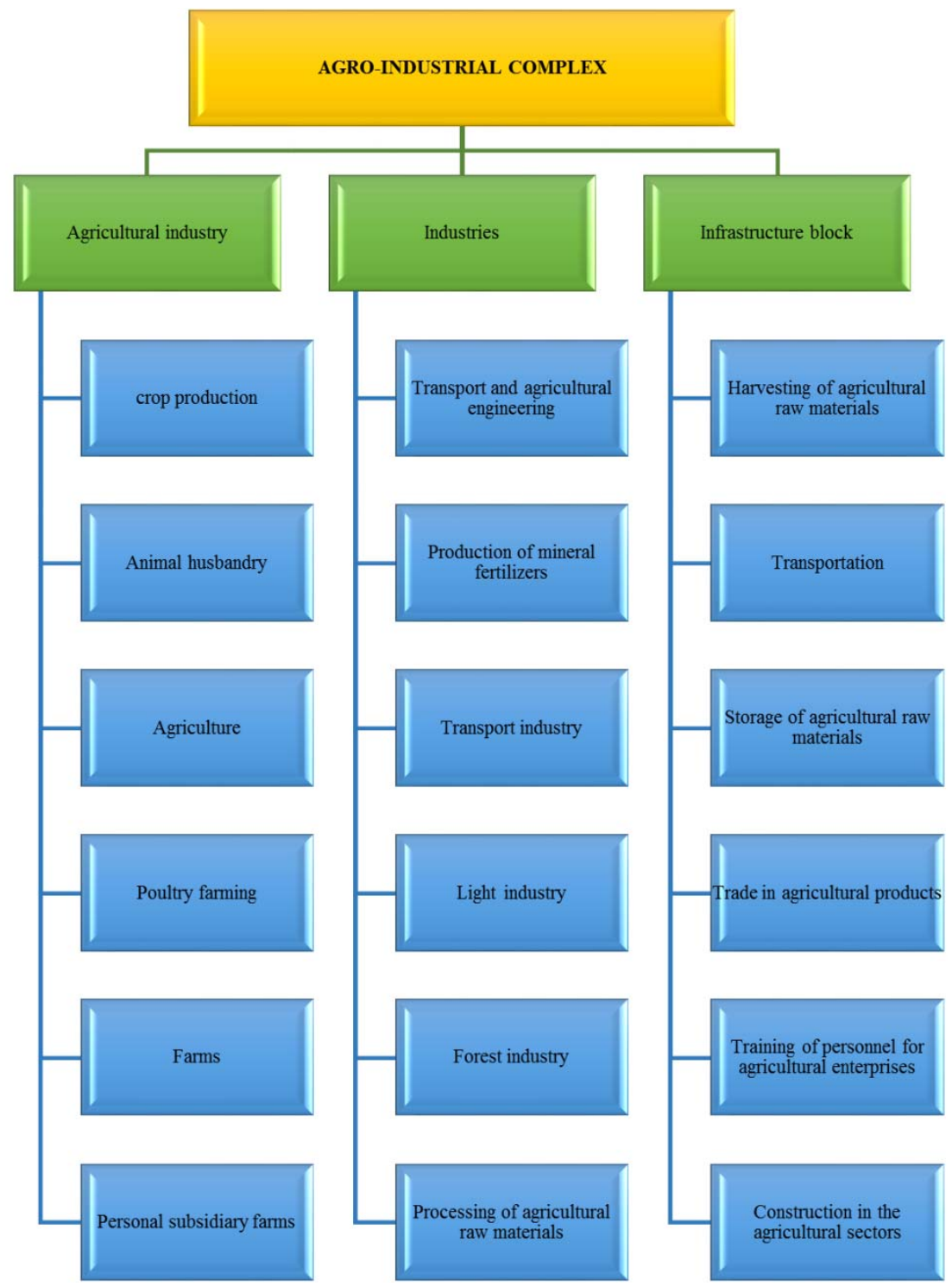

Fig. 1. Structure of the agro-industrial complex. 


\section{Materials and methods}

For the performance of transport works in the agro-industrial complex, wheeled equipment is widely used, including cars and tractors that are part of tractor-transport units.

In modern tractors, it is possible to move with a blocked drive of the drive axles, which contributes to an increase in traction properties and increased traffic safety. Transport operations carried out during the movement of tractors with a blocked drive lead to a kinematic mismatch between the wheels of the driving axles, which causes the appearance of power circulation and, accordingly, leads to an increase in fuel consumption, an increase in the load on the transmission elements, and so on. [12].

One of the possible ways to eliminate the resulting kinematic discrepancy is to maintain the air pressure in the tires at a certain level that corresponds to the operating conditions and affects the rolling radius of the wheels. The level of air pressure in the tires is inextricably linked to the fuel efficiency of the tractor, which depends on the energy loss for rolling and skidding [12].

A mathematical model has been developed to determine the rational air pressure in tires:

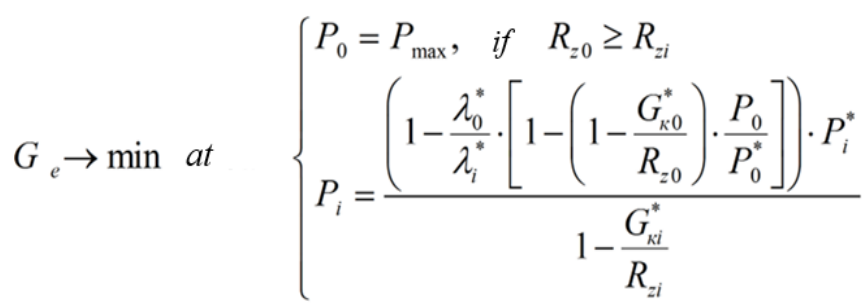

where $\mathrm{Rz}_{0}$ - is the normal reaction force acting on the wheel of the maximum loaded bridge from the side of the support surface, $\mathrm{N}$; Rzi - is the normal reaction force acting on the wheel of the minimum loaded $\mathrm{i}$-th bridge from the side of the support surface, $\mathrm{N} ; \mathrm{P}_{0}$ is the air pressure in the tires (for the wheels of the maximum loaded bridge), $\mathrm{MPa} ; \mathrm{Pi}-$ is the air pressure in the tires (for the wheels of the minimum loaded i-th bridge), $\mathrm{MPa} ;{ }_{i}^{*}, \lambda_{0}^{*}$ $\mathrm{s}$ the tangential elasticity of the tires for the wheels of the minimum and maximum loaded bridges, respectively, $1 / \mathrm{N} ; G_{\kappa i}^{*}, G_{\kappa 0}^{*}$ - he normal load of the wheel tires of the minimum and maximum loaded axles, respectively, $\mathrm{N} ;{ }^{P_{i}^{*}}, P_{0}^{*}$ - he air pressure in the wheel tires of the minimum and maximum loaded axles, respectively, MPa [12].

The presented mathematical model is made taking into account the minimum fuel consumption for the movement of a wheeled vehicle that has any (more than two) number of driving axles.

\section{Results}

Based on the presented mathematical model, a special program has been created that allows calculating the rational air pressure for wheeled vehicles with different sizes and models of tires, taking into account the load on the driving axles (Figure 2). 


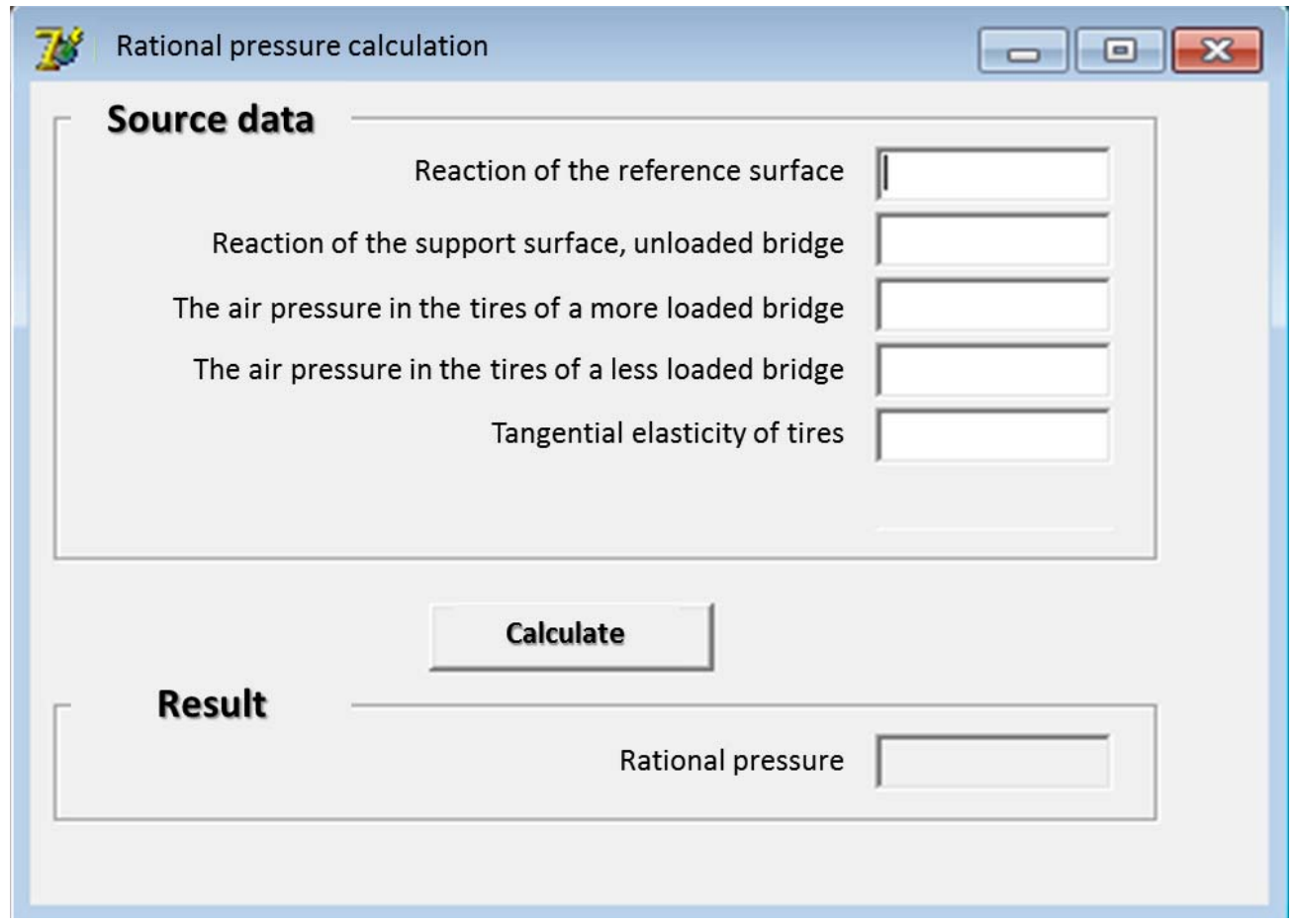

Fig. 2. Calculation program.

As a result of experimental studies, it was found that the installation of rational pressures reduces fuel consumption and increases the economic efficiency and environmental friendliness of transport (Table 1). For example, when driving on a winter road, there is a decrease in fuel consumption by $12.51 \%$ : a tractor with a $100 \%$ load of the trailer consumes $11.12 \mathrm{~kg} / \mathrm{h}$ at a rate of $12.71 \mathrm{~kg} / \mathrm{h}$ [12].

The developed program is used within the framework of the infrastructure block of the agro-industrial complex. The use of the program in the electronic information educational environment of the South Ural State Agrarian University in the training of engineers in the direction of 23.05.01 "Ground transport and technological means" and bachelors studying in the direction of 23.03.03 "Operation of transport and technological machines and complexes" contributes to the formation of professional competencies of agricultural specialists in accordance with Federal State educational standards.

\section{Conclusions}

Thus, the developed software contributes to the transfer of the information block of the agroindustrial complex to a digital basis.

Its use allows you to reduce fuel consumption, increase the economic efficiency and environmental friendliness of transportation.

The use of software in the educational process allows you to form professional competencies of agricultural specialists in accordance with Federal state educational standards. 


\section{References}

1. The program Digital Economy of the Russian Federation, http://static.government.ru/media/files.pdf.

2. Strategy for the development of the Information Society in the Russian Federation for 2017-2030 http://www.garant.ru/products/ipo/prime/doc/71570570/

3. G.P. Leshchenko, E.M. Basarygina, S.V. Cherepukhina, T.A. Putilova, International Transaction Journal of Engineering, Management and Applied Sciences and Technologies, 11(10), 11A10C (2020)

4. S. Zakharin, S. Stoyanova-Koval, I. Kychko, V. Marhasova, I. Shupta, Journal of Optimization in Industrial Engineering, 14(1), 209-218 (2021)

5. R.K. Goel, C.S. Yadav, S. Vishnoi, R. Rastogi, Sustainable Computing: Informatics and Systems, 30, 100512 (2021)

6. O.-I. Horoshko, A. Horoshko, S. Bilyuga, V. Horoshko, Technological Forecasting and Social Change, 166, 120640 (2021)

7. M.K. Chernyakov, M.M. Chernyakova, IOP Conference Series: Materials Science and Engineering, 1019(1), 012026 (2021)

8. A.Q. Jalal, Z.A. Izotova, G.I. Ivanov, E3S Web of Conferences, 224, 04038 (2020)

9. I.G. Kuznetsova, O.Yu. Voronkova, M.M. Nimatulaev, I.R. Ruiga, G.N. Zhuruli, V.E. Levichev, International Journal of Economics and Business Administration, 7, 558-569 (2019)

10. S.A. Aljawarneh, Journal of Computing in Higher Education, 32(1), 57-73 (2020)

11. I. Makarova, K. Shubenkova, D. Antov, A. Pashkevich, Lecture Notes in Networks and Systems, 47, 32-41 (2019)

12. E.A. Leshchenko, Reduction of fuel consumption in transport works by installing rational air pressures in the tires of wheeled tractors: on the example of the MTZ-82 tractor 178 (Chelyabinsk, CHGAA, 2014) 